\title{
SUSTENTABILIDADE EM CULTIVOS TRADICIONAL E HIDROPÔNICO DE ALFACE
}

Alexandra Souza Ruiz

Sulma Vanessa Souza**

Omar Jorge Sabbag**

RESUMO: Objetivou-se com este trabalho conhecer a sustentabilidade de duas unidades de produção de alface, uma na modalidade tradicional e outra na modalidade hidropônica, em Dourados - Mato Grosso do Sul, Brasil. Para avaliação da sustentabilidade, aplicou-se a ferramenta Sistema de Impacto Social de Atividades Agropecuárias (APOIA-SOCIAL), que consiste em um conjunto de planilhas eletrônicas, integradas por 16 indicadores da contribuição de uma dada atividade agropecuária. Quatro aspectos essenciais de avaliação são considerados: i) Emprego, ii) Economia, iii) Saúde e iv) Gestão e Administração. Utilizou-se o método qualitativo, caracterizado como descritivo-exploratório, fundamentados também com dados do Censo Agropecuário de 2006, realizado pelo Instituto Brasileiro de Geografia e Estatística e revisão bibliográfica. A atividade que sobressaiu foi a horticultura hidropônica, que obteve 0,73 de índice de sustentabilidade, valor acima da linha de base de utilidade dos indicadores (igual a 0,70 ). Apesar do desempenho satisfatório, alguns indicadores apresentaram valores de utilidade baixos, podendo prejudicar a sustentabilidade das atividades nestas unidades de produção familiar.

PALAVRAS-CHAVE: Hidropônico; Lactuca sativa L.; Sustentabilidade; Tradicional.

\section{SUSTAINABILITY IN TRADITIONAL CROPS AND IN HYDROPONIC CULTURE OF LETTUCE}

ABSTRACT: The sustainability of two production units of lettuce, the traditional and the hydroponic culture, in Dourados MS Brazil, is analyzed. Sustainability was evaluated by the System of Social Impact of Agro-livestock Activities (APOIA-

\footnotetext{
${ }^{*}$ Mestra em Desenvolvimento Regional e de Sistemas Produtivos (PPGDRS), Universidade Estadual de Mato Grosso do Sul (UEMS), Brasil. E-mail: ale.souza.ruiz@gmail.com

${ }^{* *}$ Mestranda em Desenvolvimento Regional e de Sistemas Produtivos (PPGDRS), Universidade Estadual de Mato Grosso do Sul (UEMS), Brasil.

** Pós-doutor em Zootecnia. Docente da Universidade Estadual Paulista Júlio de Mesquista Filho (UNESP/FEIS) e do programa de pós-graduação em Desenvolvimento Regional e de Sistemas Produtivos da Universidade Estadual de Mato Grosso do Sul (UEMS), Brasil.
} 
SOCIAL), with a set of electronic sheets, integrated by 16 indexes of contribution from a specific agro-livestock activity. Four essential evaluation aspects were taken into account: i) employment, ii) economy, iii) health and iv) management and administration. The Qualitative, descriptive and exploratory method was employed. It was based on data from the 2006 Agro-Livestock Census by the Brazilian Institute of Geography and Statistics, and on bibliographic review. Hydroponic horticulture was highlighted with a 0.73 sustainability index. This rate was above the base line of indicators $(=0.70)$. In spite of satisfactory performance, some indicators had low use rates and may jeopardize the sustainability of activities within the family production units.

KEY WORDS: Hydroponic crops; Lactuca sativa L.; Sustainability; Traditional.

\section{INTRODUÇÃO}

A alface (Lactuca sativa L.) é uma hortaliça folhosa de grande importância econômica e alimentar para a população brasileira, e seu consumo vem aumentando devido à mudança no hábito alimentar da população. Isso deve-se ao fato de ser fonte de vitaminas e sais minerais, além de apresentar baixo valor calórico (MONTEIRO et al., 2015).

A alface se destaca por ser a folhosa mais consumida no Brasil na atualidade (IBGE, 2017). Os dados do censo agropecuário de 2006 apontam uma produção nacional em torno de 525.602 toneladas de alface ao ano, contando com a participação de 66.301 estabelecimentos. Em 2015, a alface foi responsável por $47 \%$ da movimentação pecuniária do mercado de folhosas (UDSEN, 2016).

Dada sua capacidade de adaptação a diferentes condições climáticas e possibilidade de vários cultivos ao longo do ano, essa folhosa é uma das culturas de maior preferência dos pequenos produtores (MEDEIROS et aI., 2007). Conforme Villas Bôas et al. (2004), a cultura da alface pode ser considerada como um fator de agregação do homem ao campo.

Salienta-se ainda que essa hortaliça pode ser produzida em diversas modalidades de cultivo. Uma das modalidades é o cultivo tradicional (produção diretamente na área de interesse, ou seja, em solos férteis). Outra modalidade é o cultivo hidropônico, em que se utiliza água e substâncias nutritivas nela diluídas (solução nutritiva), para a manutenção e o desenvolvimento da produção. 
Nesse contexto, torna-se relevante a busca por um sistema de produção que otimize a eficiência produtiva, proporcione rentabilidade e que não agrida os recursos naturais renováveis, isto é, mais sustentáveis, que construam conhecimentos e alternativas tecnológicas, possibilitando novas formas de fazer agricultura, com a utilização de princípios, métodos e tecnologias de base agroecológicas.

De acordo com a Agenda 21 (1992), a sustentabilidade apoia-se em um tripé marcado pela viabilidade econômica, equilíbrio ecológico e equidade social. Dessa forma, como sugerido por Nexton (2003), esses três domínios da sustentabilidade devem ser tratados com paridade; entretanto, dentre essas, a dimensão social é pouco discutida quando relaciona-se a sistemas de produção.

Por sua vez, para Barreto (2004), a nova concepção de sustentável traz em si alterações fundamentais que enfatizam o social, aludindo a melhoria da qualidade de vida, consumo real per capita, diminuição dos níveis de pobreza, desemprego, desigualdade social, aumento das condições de educação, moradia digna, dentre outros. Assim, o desafio da sustentabilidade não se restringe a questões ambientais, como também econômicas e sociais, uma vez que busca garantir a satisfação das necessidades atuais, não podendo comprometer o meio ambiente e criar dificuldades para as gerações futuras.

Percebe-se que em Mato Grosso do Sul, somente nos últimos anos, vem aumentando a procura de sistemas de produção sustentáveis, em especial aquelas que podem ser cultivadas em pequenas áreas, como é o caso das hortaliças. Esse fato é consequência da proliferação de chácaras e agrovilas, ao redor das maiores cidades do Estado, possibilitando assim a formação de cinturões verdes, com a venda de produtos diretamente aos supermercados e aos consumidores. Corroborando, Zárate e Vieira (2005) confirmam a necessidade de pesquisas para as principais hortaliças comercializadas, dentre elas: alface, alho, beterraba, cenoura, cebola e milho-verde. Portanto, evidencia-se que a preocupação do produtor não pode restringir-se apenas à produtividade e à qualidade da produção pretendida, mas principalmente como ela será obtida (CECÍLIO FILHO, 2008).

Dentre as ferramentas de verificação da sustentabilidade dos sistemas de produção com ênfase na dimensão social, pode-se citar o Sistema de Avaliação de Impacto Social de Atividades Agropecuárias (APOIA SOCIAL), criado pela Empresa Brasileira de Pesquisa Agropecuária (EMBRAPA), que considera quatro aspectos 
(emprego, economia, saúde, gestão e administração) e 16 indicadores (RODRIGUES et al., 2005). Esse sistema objetiva diagnosticar os pontos desconformes para correção e alcançar a sustentabilidade do estabelecimento rural, bem como diagnosticar as principais vantagens comparativas da atividade no estabelecimento, no sentido de contribuir para o desenvolvimento local sustentável (RODRIGUES; CAMPANHOLA, 2003).

Assim, objetivou-se realizar uma abordagem por meio de indicadores na análise de sustentabilidade social de sistemas de produção de alface.

\section{MATERIAL E MÉTODOS}

O estudo foi desenvolvido no município de Dourados (Latitude: 22.2218, Longitude: $54.806422^{\circ} 13^{\prime} 18^{\prime \prime}$ Sul, $54^{\circ} 48^{\prime} 23^{\prime \prime}$ Oeste), localizado na porção meridional do Estado do Estado de Mato Grosso do Sul (MS), entre a Serra de Maracaju e a bacia do Rio Paraná, situado na região Centro-Oeste do Brasil (Figura 1), com área total de $4.086,237 \mathrm{~km}^{2} \mathrm{e}$ área urbana de $40,68 \mathrm{~km}^{2}$, possui uma população de 215.486 habitantes (52,7 habitantes por $\left.\mathrm{km}^{2}\right)$, segundo dados do Instituto Brasileiro de Geografia e Estatística (IBGE, 2016).

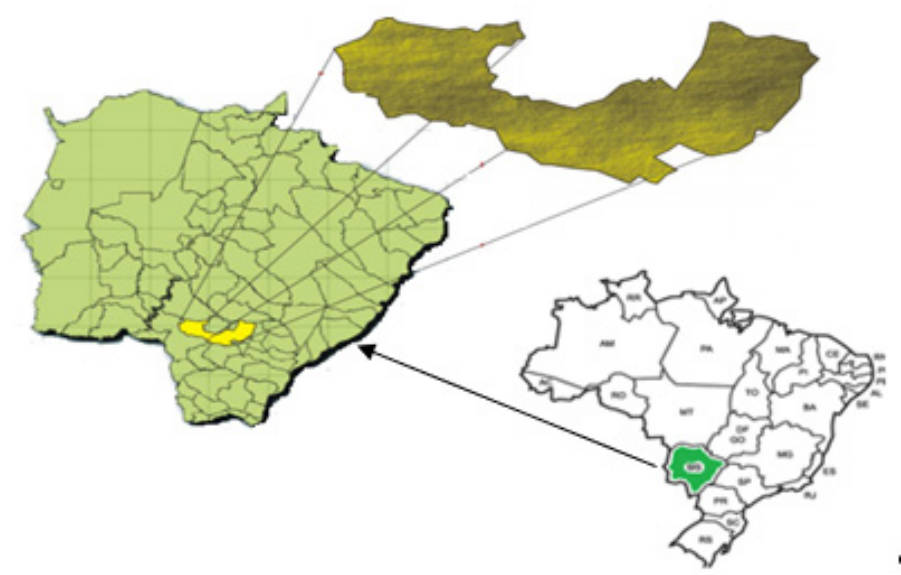

Figura 1. Município de Dourados (MS).

Fonte: Base Cartográfica IBGE, 2017 - adaptado pelos autores. 
Utilizou-se o método qualitativo, que se caracteriza como sendo exploratóriodescritivo. Para Malhotra (2001), a pesquisa exploratória é utilizada em casos nos quais é pertinente definir o problema com maior precisão, e o seu objetivo é prover critérios e compreensão; já as pesquisas descritivas, de acordo com Gil (2008), buscam descrever as características de determinadas populações ou fenômenos, uma de suas características está na utilização de técnicas padronizadas como, por exemplo, a coleta de dados.

A pesquisa utilizou amostra intencional (não probabilística), correspondendo a duas propriedades localizadas no município de Dourados (MS) (Figuras 2A e 2B), sendo uma na modalidade tradicional (propriedade com 0,6 ha, que está na atividade desde 1995, utiliza defensivos químicos, produtor familiar) e outra na modalidade hidropônica (propriedade com 6 ha, atua no ramo desde 2012, utiliza defensivos químicos, produtor familiar). A técnica utilizada foi a entrevista semiestruturada, com aplicação de um questionário contendo questões fechadas, que atendessem aos aspectos previstos na ferramenta Apoia Social. Gil (2008, p. 112) explica que "o entrevistador permite ao entrevistado falar livremente sobre o assunto, mas, quando este se desvia do tema original, esforça-se para a sua retomada”. As entrevistas foram realizadas durante o mês de abril de 2017.

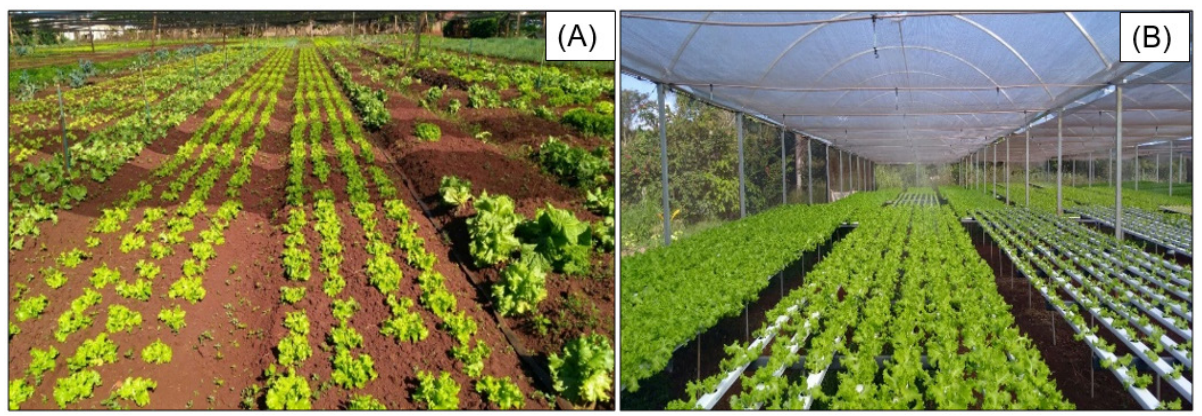

Figuras 2. Produtor tradicional (A) e produtor hidropônico (B). Fonte: Elaborado pelos autores.

Em relação ao Sistema APOIA-Social, os indicadores são construídos em matrizes de ponderação, nas quais os dados são obtidos no campo, considerando os conhecimentos do produtor ou do administrador, em seguida são automaticamente 
transformados em índices de impacto expressos graficamente. O índice de impacto de cada indicador é traduzido em valor de utilidade ( 0 a 1), empregando-se funções e coeficientes especificamente derivados para cada indicador. Finalmente, os valores de utilidade para todos os indicadores são agregados, para compor o índice de impacto social da tecnologia, que atingindo a partir de 0,7 , já é considerado positivo (RODRIGUES; CAMPANHOLA, 2003).

A composição das curvas de correspondência entre os indicadores e o desempenho ambiental definido em valores de utilidade baseou-se em testes de sensibilidade e de probabilidade, para cada indicador (GIRARDIN; BOCKSTALLER; VAN DER WERF, 1999).

As curvas de correspondência entre os índices de impacto dos indicadores e os valores de utilidade (as funções de transformação) são expressas em equações multicoeficientes, derivadas caso a caso, com ajustes mínimos correspondentes a $\mathrm{R}^{2}=0,95$ (HYAMS, 1995). As equações e coeficientes foram inseridos nas matrizes de ponderação e vinculadas aos índices de impacto, traduzindo-os diretamente em valores de utilidade para expressão gráfica e cálculo do índice de impacto social da atividade agropecuária para cada indicador.

Neste contexto, a dimensão social fundamenta-se em quatro aspectos capazes de abranger os temas relativos a: i) qualidade de vida da população incluída no processo produtivo, ii) geração e oportunidade de emprego qualificado, iii) renda (que não somente retrata o valor da terra e o rendimento, mas a distribuição de renda) e iv) qualificação do responsável, inserção no mercado e cuidados com a reciclagem dos resíduos, traduzidos na gestão e na administração do estabelecimento (Figura 3). 


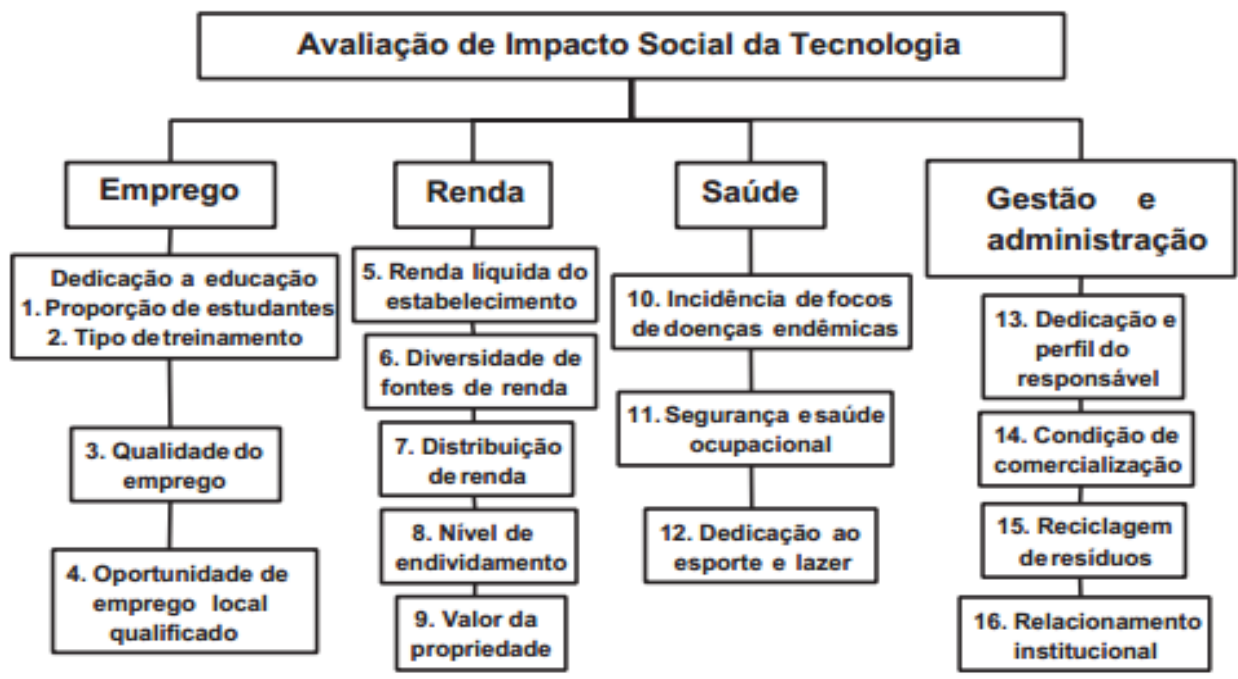

Figura 3. Aspectos e indicadores do Sistema de Avaliação de Impacto Social de Inovações Tecnológicas Agropecuárias (APOIA-Social).

Fonte: Rodrigues e Campanhola, 2003.

\section{RESULTADOS E DISCUSSÃO}

Inicialmente, os índices demonstraram que somente o produtor hidropônico alcançou resultado de impacto social um pouco acima da linha de base $(0,70)$ preconizada pelo sistema, inferindo que o impacto social do cultivo hidropônico foi favorável em comparação ao cultivo tradicional, conforme dados da Tabela 1.

Tabela 1. Índices de desempenho (APOIA-SOCIAL) produtor tradicional e produtor hidropônico. Região de Dourados (MS) (2017)

\begin{tabular}{lcc}
\hline Aspectos & Tradicional & Hidropônica \\
\hline Emprego & 0,45 & 0,46 \\
Economia & 0,78 & 0,83 \\
Saúde & 0,36 & 0,19 \\
Gestão e Administração & 0,30 & 0,53 \\
Índice de Impacto Social & 0,67 & 0,73 \\
\hline
\end{tabular}

Fonte: Elaborado pelos autores, com base nos dados da pesquisa. 
$\mathrm{Na}$ modalidade tradicional, o índice gestão e administração obteve menor resultado $(0,30)$, influenciado por alguns fatores, dentre os quais: falta de acompanhamento contábil (nenhuma anotação de entrada e saída de recursos), ausência de investimento em marketing, não haver processamento local e nem encadeamento de atividades, sendo todas as atividades realizadas apenas pelo proprietário e filhos.

Quanto à modalidade hidropônica, contando com seis trabalhadores na propriedade, o menor índice correspondeu no aspecto saúde $(0,19)$. Este fato foi decorrente à total ausência de cuidados com a segurança e saúde ocupacional (periculosidade e insalubridade), como também a ausência de preocupação com acesso a esportes (lazer). Observou-se também que o aspecto economia destacouse positivamente em ambas as atividades de cultivo, atingindo 0,78 no produtor tradicional e 0,83 no produtor hidropônico, evidenciando o foco das atividades em obter resultado econômico.

\subsection{ASPECTO EMPREGO}

O aspecto emprego é qualificado segundo a proporção de cada uma das categorias de ocupação, com garantia de atendimento a condições básicas como idade, jornada de trabalho, formalidade e auxílios e benefícios previstos pelas leis trabalhistas brasileiras, as ponderações acusaram equilíbrio entre as propriedades analisadas (tradicional/hidropônico), correspondendo ao índice 0,45 para o cultivo tradicional e 0,46 para a horticultura hidropônica, porém ambas apresentam impactos negativos, como o baixo estímulo à empregabilidade, em que nenhum dos produtores analisados atendem satisfatoriamente às necessidade dos empregados (por exemplo, na modalidade tradicional os trabalhadores não possuem carteira registrada).

O trabalho local não é qualificado, sendo executado em sua maioria de forma braçal e não há investimentos em treinamento especializado. Por consequência, diminuem as possibilidades de encadeamento de novas atividades produtivas, bem como na melhora da produtividade nas propriedades pesquisadas.

Destaca-se que na propriedade A não há nenhum membro em estudos; e 
na propriedade B apenas os filhos do produtor, sendo os empregados excluídos do ambiente educacional.

Assim, estes impactos são oriundos de uma ausência de treinamento constante no local correspondente à atividade agrícola, especialização de curta duração e cursos oficiais (nível fundamental e médio) em relação aos residentes na propriedade, entretanto apenas um deles possui empregado especializado, assim como assessoria legal. Neste sentido, a transferência de tecnologia passa a ser necessária, de forma a atingir uma melhor performance no cultivo desenvolvido pelos produtores. Segundo Dereti (2009), a expressão "transferência de tecnologia" surgiu em substituição ao termo difusão, visando à incorporação de recursos de ordem tecnológica, que possibilitem aumentos de produção e de produtividade, consequentemente proporcionando crescimento econômico a partir do uso racional dos recursos naturais.

Por sua vez, Feder e Umali (1993) entendem que melhorias na produtividade e na qualidade do produto final, aumentando assim o bem-estar econômico e social, não são propriamente com relação ao desenvolvimento de novas tecnologias, mas à rapidez e extensão a sua aplicação em áreas comerciais. Dessa forma, quanto mais rapidamente uma tecnologia é adotada, maior é a melhoria do bem-estar social, bem como a renda. No entanto, entendem que se tornam necessárias correções em tais intervenções, já que grande parte da pesquisa sobre a adoção de tecnologias agropecuárias ainda se baseia nos progressos realizados no ciclo de difusão de tecnologias da "Revolução Verde".

\subsection{ASPECTO ECONOMIA (RENDA)}

A performance do indicador economia nas atividades pesquisadas atingiram índices acima do valor preconizado para a linha de base, reforçando que as atividades exercidas nas propriedades trouxeram benefícios aos produtores, obtendo-se 0,78 para o produtor tradicional e 0,83 para o produtor hidropônico. Houve um considerado aumento da renda com a implementação da tecnologia avaliada, como também foi verificado aumento no valor da terra.

Quanto à questão do endividamento, um dos agricultores (tradicional) optou 
por não dispor de investimentos externos, aplicando somente recursos financeiros próprios, livre de financiamento externo. Com relação ao padrão de consumo, percebeu-se que houve uma maior aquisição de bens móveis na propriedade de cultivo tradicional; já na propriedade hidropônica, manteve-se estável o patrimônio. O modelo tecnológico permitiu aumento na estabilidade no montante e na segurança da renda de todos os produtores.

De acordo com Rossetti (1990), as necessidades dos seres humanos são ilimitadas, enquanto os recursos são escassos, cabendo à economia a difícil tarefa de estabelecer alocação entre ambos. Partindo desse pressuposto, o consumo exagerado, sem consciência, estimula o aumento dos preços dos produtos, que por sua vez eleva o nível de inflação, desvalorizam a renda pessoal disponível e lançam consumidores aos empréstimos e possíveis endividamentos, gerando um desequilíbrio financeiro.

O planejamento financeiro, de acordo com Santos (1984), significa ordenar a vida financeira de tal maneira que permita ao indivíduo possuir reservas para os imprevistos e sistematicamente construir um patrimônio, seja ele financeiro ou imobiliário, que garanta fontes de renda suficientes para propiciar uma vida tranquila e confortável.

\subsection{ASPECTO SAÚDE}

Já no aspecto saúde, os resultados foram bem aquém da base, gerando impactos negativos, dentre os quais a incidência de focos de vetores de doenças endêmicas, não preocupação quanto aos procedimentos de segurança e saúde ocupacional, bem como baixo estímulo ao esporte e lazer, atingindo percentual de 0,36 na atividade tradicional e 0,19 na atividade hidropônica.

Quanto à incidência de foco de vetores, a principal causa foi decorrente da presença da Bemisia tabaci, conhecida como mosca-branca. Atualmente é considerada como a praga mais atuante no país, atacando diversas culturas (soja, feijão, tomate, melancia, etc.). Isso ocorre em função dessas culturas serem fonte de alimentação, dado que esse inseto se alimenta da seiva das plantas (NARCISO et al., 2013).

Nesse contexto, os produtores alegam que em função das medidas 
profiláticas, ainda conseguem manter o foco sob controle; entretanto, não conseguem erradicá-lo. Os produtores entrevistados possuem conhecimento sobre tais medidas, inclusive no correto uso de defensivos químicos.

Logo, cabe ao produtor manter as medidas preventivas necessárias à contenção dessas pragas. Dentre essas pode-se citar: plantio de mudas sadias; uso de barreiras vivas, como por exemplo o plantio do milho, que impedem ou retardam a entrada de mosca-branca na lavoura; cumprimento de normas de plantio; uso de armadilhas e eliminação de restos culturais, sendo que estes devem ser incorporados ao solo logo após a colheita (LACERDA; CARVALHO, 2008).

Para a análise do indicador segurança e saúde ocupacional foram considerados se a atividade expóe o colaborador a fatores de periculosidade e de insalubridades. Tanto o produtor tradicional quanto o produtor hidropônico enfatizaram que suas atividades não expõem seus funcionários a tais riscos.

Dessa forma, mesmo não sendo considerado como risco na visão dos produtores entrevistados, é pertinente reforçar que "quando armazenados perfeitamente, produtos fitossanitários proporcionam pouco risco à saúde das pessoas e ao meio ambiente (MUNIZ; TELES, 2013). Portanto, o produtor deve seguir respeitosamente as normas de segurança e armazenagem dos defensivos, na intenção de evitar a contaminação denominada cruzada (inseticidas ou fungicidas com herbicidas) (MUNIZ; TELES, 2013).

Além disso, os produtores devem utilizar corretamente os equipamentos de proteção individual (EPI's) durante a aplicação dos agrotóxicos, para se protegerem contra possíveis contaminações/intoxicações (MALDONADE; MATTOS; MORETTTI, 2014).

Quanto ao indicador dedicação a esporte e lazer foi o índice mais agravante para ambos produtores, pois não disponibilizam atividades de esporte e lazer aos seus colaboradores. Samulski (1992) enfatiza que a prática de esporte pelos funcionários é de extrema importância, em razão de auxiliar no desenvolvimento psicológico, nas relações humanas, na socialização, assim como na autoconfiança.

Já o aspecto lazer, de acordo com Nascimento e Pessoa (2008), consegue humanizar o ambiente de trabalho, ampliar o índice de satisfação e integração dos funcionários e consequentemente maximizar o retorno e o lucro. Além de prevenir o estresse e o cansaço ocasionado pelo trabalho, o lazer também auxilia nas relações 
interpessoais e na vida social do indivíduo, correspondendo como um tema de extrema relevância no que se refere ao desenvolvimento saudável no trabalho (MUNIZ; GHIRALDELLO, 2014).

\subsection{ASPECTO GESTÃO E ADMINISTRAÇÃO}

Quanto ao aspecto gestão e administração, os dois produtores apresentaram índice abaixo da média, sendo o produtor hidropônico com índice 0,53 e o produtor tradicional com 0,30 . Esses resultados ocorreram em função da maioria dos indicadores analisados, dentre os quais perfil do produtor, comercialização e disposição de resíduos tornarem-se limitados quanto à sua melhor performance.

Com base no exposto, Silva (2013) salienta que a falta de conhecimento sobre os princípios básicos da administração torna o produtor rural vulnerável, inferindo ainda que qualquer investimento tende a fracassar quando mal administrado.

Tomei e Souza (2014), ao desenvolverem um estudo sobre as barreiras que dificultam a transformação do agricultor familiar em empreendedor rural, apontaram como principais resultados a ausência de liderança, capacidade de assumir riscos e a carência por educação formal.

Na mesma linha, segundo Lima, Parteli e Loose (2015), os agricultores familiares necessitam trabalhar o empreendedorismo como estratégias de fortalecimento, na intenção de que possam utilizar todos os recursos disponíveis para criar novos produtos e serviços ou aperfeiçoar os que já estão sendo produzidos.

$\mathrm{Na}$ mesma perspectiva, Antonini (2012) enfatiza que a gestão é um fator base para o sucesso e sobrevivência de qualquer propriedade; desta forma, o gestor deve estar atento ao ambiente interno e externo, aperfeiçoando-se constantemente para acompanhar o mercado. A administração rural pode representar fator de sucesso para o produtor rural, desde que o mesmo conheça os conceitos básicos e os apliquem (SILVA, 2013).

Ainda de acordo com Gaffuri et al. (2005), o correto gerenciamento do empreendimento rural é um dos fatores essenciais para que a propriedade alcance a sustentabilidade como um todo, sendo imprescindível a inclusão de novas técnicas de gestão e estratégias nas atividades realizadas dos agricultores familiares. 
Quanto à condição de comercialização, os valores são justificados pela condição de comercialização apresentada nas propriedades. O produtor tradicional comercializa através de venda direta na própria propriedade e não possui interesse em fazer parceria nem com os mercados locais, tornando-se um fluxo comercial restrito. Quanto ao produtor hidropônico, este realiza venda direta tanto na propriedade, quanto em mercados, efetuando entregas diariamente. Ambos os produtores não dispõem de marca própria, não utilizam veículos de propaganda, fatos que somados aos demais índices baixos colaboraram para que as duas propriedades obtivessem um índice inferior à linha base.

Diante do cenário atual, onde há um acirramento econômico, comercializar produtos de maneira eficiente é um dos grandes desafios enfrentados pelas empresas, assim como pelo setor de marketing (LAGO et al., 2006). Como tática, o marketing lida com as atividades rotineiras da gestão do produto, determinação de preço, distribuição e comunicação de marketing, como a propaganda, a venda pessoal, a publicidade e a promoção de vendas (LIMA; PARTELI; LOOSE, 2015). No tocante ao lucro, o marketing tem como propósito aumentar a venda na intenção de remunerar os investidores (TRENTIN et al., 2006).

$\mathrm{O}$ indicador reciclagem dos resíduos apresentou resultados indesejáveis, haja vista que nenhum dos produtores efetua coleta seletiva, não possuem disposição sanitária e não realizam compostagem. Por outro lado, percebe-se que as duas propriedades realizam reaproveitamento de resíduos (água), bem como destinação correta e tratamento final desses resíduos líquidos. Palhares (2005) sinaliza que uma construção sustentável se fundamenta na correta gestão, prevenção e redução dos resíduos de forma adequada e com menor custo possível. Diante disso, tornase necessário que os produtores adotem modelos de gestão de resíduos, dado o aspecto de inesgotabilidade inerente aos resíduos (PEREIRA; CURI, 2013).

Os resultados referentes ao relacionamento institucional apresentaram índices abaixo da linha de base, haja vista que todas as propriedades não dispuseram de assistência técnica e não serem vinculados às organizações coletivas (como associações e cooperativas). Nesses termos, Mendes (2005) enfatiza que a adoção de diferentes estratégias sociais e econômicas pelos produtores rurais, como, por exemplo, o associativismo, tem viabilizado e auxiliado para a inserção dos produtores 
no mercado e na sociedade. "A finalidade de uma associação, portanto, consiste em relacionar, de maneira democrática, os agentes com objetivos em comum" (SANGALLI et al., 2015, p. 228).

Abramovay (2000) traz importantes considerações sobre o uso das redes sociais e do capital social, como instrumento para o desenvolvimento rural. $\mathrm{O}$ autor destaca a importância para os projetos de desenvolvimento rural, que permitem ações cooperativas que incluem a conquista de bens públicos como educação, saúde e informação.

Com esses resultados, o índice de impacto social das atividades analisadas calculado pela média dos valores de utilidade do conjunto de indicadores alcançou 0,63 para o produtor tradicional (Figura 4) e 0,70 para o produtor hidropônico (Figura 5), o que indica para este último um valor de linha base, sendo já considerado sustentável comparativamente ao tradicional, o que ainda torna-se necessário otimizar o desempenho da produção a contribuir para o bem-estar do empreendimento rural, bem como para o desenvolvimento local.
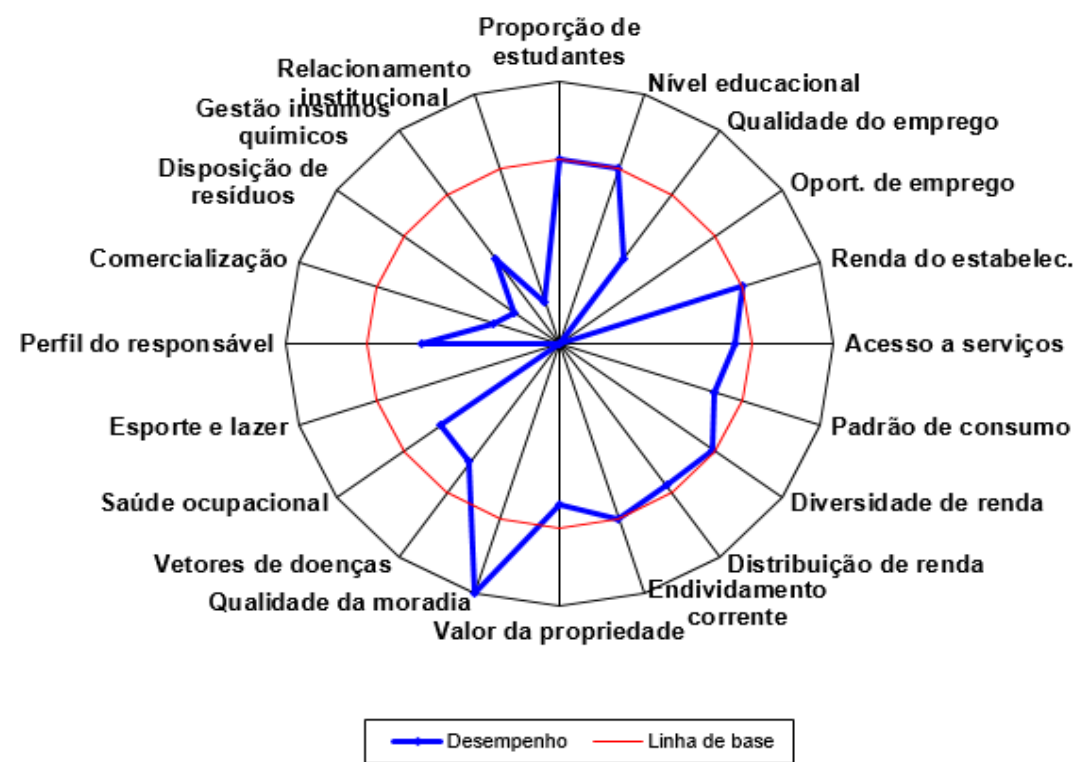

Índices de Desempenho dos Indicadores Sociais

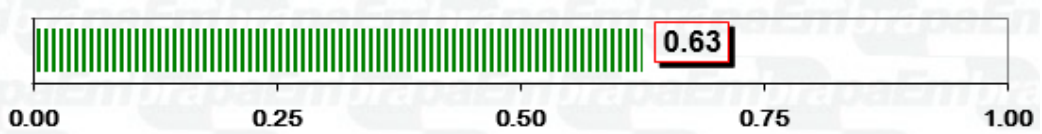




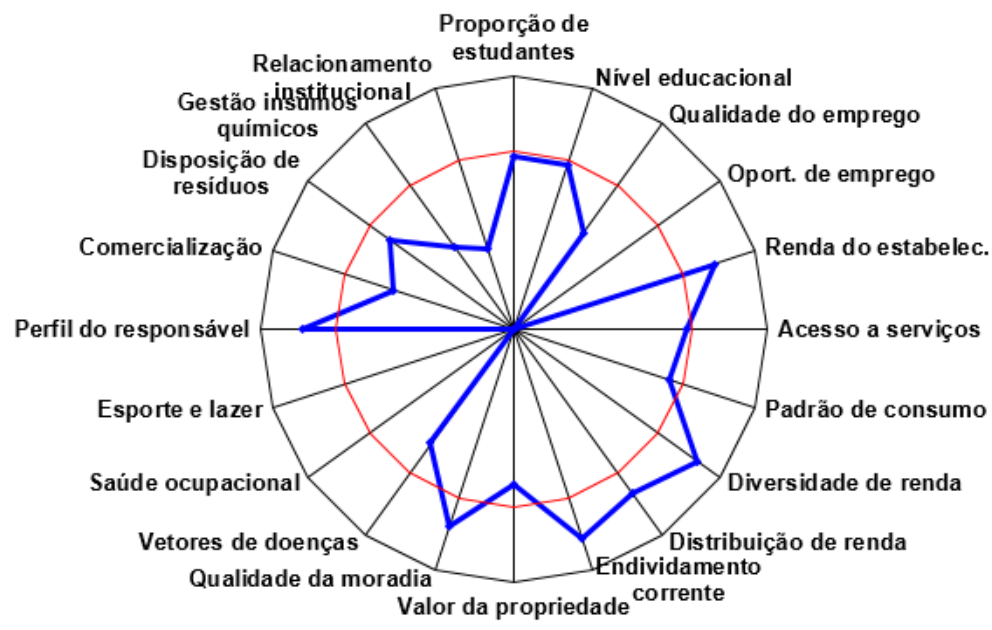

- Desempenho Linha de base

Índices de Desempenho dos Indicadores Sociais

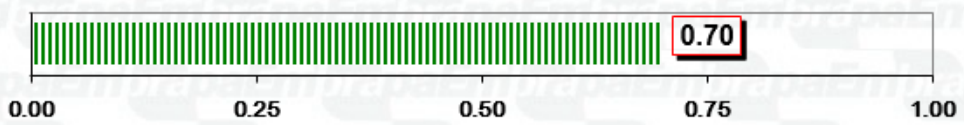

Figura 5. Resultados da avaliação de impacto social - Produtor hidropônico.

Fonte: Elaborado pelos autores, a partir dos resultados da pesquisa.

Neste contexto, o APOIA-Social representa uma ferramenta útil e hábil que pode auxiliar aos produtores bem como os formuladores e gestores públicos, contribuindo inclusive para o desenvolvimento local, facilitando a definição de medidas de promoção ou controle da atividade.

Vale ainda ressaltar que o comparativo das atividades de produção de alface tradicional e hidropônica permite verificar os principais pontos de estrangulamento a serem supostamente corrigidos por melhorias na condução de manejo, bem como na qualificação profissional, seleção e transferência de tecnologias agrícolas, por meio de melhores investimentos na atividade condizentes aos diferentes aspectos avaliados. 


\section{CONCLUSÃO}

A avaliação da ferramenta APOIA-social apontou o aspecto economia da atividade hidropônica como o principal diferencial para ambas atividades, representando de forma limitada o lucro econômico como principal fator preponderante no cultivo da alface.

Por outro lado, os demais indicadores para ambas propriedades apresentaram níveis indesejáveis, limitando o aumento do impacto social nas propriedades analisadas, demonstrando que os indicadores merecem maior atenção e monitoramento em sua execução, para que o desenvolvimento rural se torne mais eficiente e eficaz.

De forma geral, constata-se que o Apoia Social pode permitir avanços no bem-estar social dos produtores, além de promover a sustentabilidade desses estabelecimentos.

\section{REFERÊNCIAS}

ABRAMOVAY, R. O capital social dos territórios: repensando o desenvolvimento rural. In: SEMINÁRIO SOBRE REFORMA AGRÁRIA E DESENVOLVIMENTO SUSTENTÁVEL, 1998, Fortaleza. Reforma Agrária e desenvolvimento sustentável. Brasília: Ministério do Desenvolvimento Agrário, Núcleo de Estudos Agrários e Desenvolvimento, p. 1-15, 2000.

AGENDA 21. Conferência das Nações Unidas sobre o meio ambiente e desenvolvimento. Brasília, 1992. Disponível em: http://www.onu.org.br/rio20/ img/2012/01/agenda21.pdf. Acesso em: 29 dez. 2017.

ANTONINI, F. T. A importância do planejamento estratégico para empresas de Agronegócios. 2012. 24f. (Especialização em Ciências Contábeis) - Faculdade de Ciências Contábeis e Administração do Vale do Juruena, Instituto Superior de Educação do Vale de Juruena, Nova Xavantina, 2012. 
BARRETO, R. C. S. Políticas públicas e o desenvolvimento rural sustentável no Estado do Ceará: um estudo de caso. 2004. 91f. Dissertação (Mestrado em Economia Rural) - Universidade Federal do Ceará, Fortaleza, 2004.

CECÍlIO FILHO, A. B.; REZENDE, B. L.; BARBOSA, J. C.; FELTRIM, A. L.; SILVA, G. S. da; GRANGEIRO, L. C. Interação entre alface e tomateiro consorciados em ambiente protegido, em diferentes épocas. Horticultura Brasileira, Brasília, v. 26, n. 2, p. 158-164, 2008.

DERETI, R. M. Transferência e validação de tecnologias agropecuárias a partir de instituições de pesquisa. Desenvolvimento e Meio Ambiente. Curitiba, n. 19, p. 29-40, 2009.

FEDDER, G.; UMALI, D. L. The adoption of agricultural innovations: a review. Technological Forecasting and Social Change, New York, v. 43, p. 215-239, 1993.

GAFFURI, J.; TEODORO, P. A. V. B.; MIYAZAKI, J.; SCHMIDT, R. M.; NAZZARI, R. K.; BERTOLINI, G. R. Empreendedores rurais como gestores de negócio para o provimento do desenvolvimento agrícola. In: SEMINÁRIO NACIONAL ESTADO E POLÍTICAS SOCIAIS NO BRASIL, 2., 2005. UNIOESTE, Cascavel, p. 07, 2005. Disponível em: http://cac-php.unioeste.br/projetos/gpps/midia/seminario2/trabalhos/economia/ meco13.pdf. Acesso em: 16 fev. 2018.

GIL, A. C. Métodos e Técnicas de Pesquisa Social. 6. ed. São Paulo: Atlas, 200 p, 2008.

GIRARDIN, P.; BOCKSTALLER, C.; VAN DER WERF, H. Indicators: tools to evaluate the environmental impacts of farming systems. Journal of Sustainable Agriculture, California, v. 13, n. 4, p. 5-21, 1999.

HYAMS, D. CurveExpert Version 1.37: a curve fitting system for Windows. Seattle: Microsoft, 1995. Software. 1 CD-ROM. 
IBGE. Instituto Brasileiro de Geografia e Estatística. Dados estatísticos. Disponível em: http://www.ibge.gov.br/home/. Acesso em: 24 abr. 2017.

LACERDA, J. T.; CARVALHO, R. A. Descrição e manejo integrado da mosca-branca (Bemisia spp.) transmissora de geminivirus em culturas econômicas. Tecnologia \& Ciência Agropecuária, João Pessoa, v. 2, n. 2, p. 15-22, jun. 2008.

LAGO, A.; LENGLER, L.; CORONEL, D. A.; SILVA, T. N. Agricultura Familiar de Produtos Orgânicos: um olhar sob a ótica do marketing. Revista Extensão Rural, DEAR/CPGExR-CCR-UFSM, Santa Maria, Ano XIII, jan-dez., p. 94-116, 2006.

LIMA, C. C.; PARTELI, L. F.; LOOSE, C. E. O empreendedorismo rural e a agroindústria familiar na gestão da atividade agropecuária em Rondônia. Revista de Administração e Contabilidade, Santo Ângelo, v. 14, n. 27, p. 97-134, 2015.

MALDONADE, I. R.; MATTOS, L. M.; MORETTI, C. L. Manual de boas práticas agrícolas na produção de alface. Empresa Brasileira de Pesquisa Agropecuária. Documentos 142, 2014. Disponível em: https://www.researchgate.net/publication /272829282_Manual_de_boas_praticas_agricolas_na_producao_de_alfacepdf. Acesso em: 17 fev. 2018.

MALHOTRA, N. Pesquisa de marketing. 3. ed. Porto Alegre: Bookman, 720 p., 2001.

MEDEIROS, D. C.; LIMA, B. A. B.; BARBOSA, M. R.; ANJOS, R. S. B.; BORGES, R. D.; CAVALCANTE NETO, J. G.; MARQUES, L. F. Produção de mudas de alface com biofertilizantes e substratos. Revista Horticultura Brasileira, Brasília, v. 25, n. 3, p. 433-436, 2007.

MENDES, E. P. P. A Produção rural familiar em Goiás: as comunidades rurais no município de Catalão (GO). 2005. 294f. Tese (Doutorado) - Universidade Estadual Paulista, Faculdade de Ciências e Tecnologia - Presidente Prudente, 2005. 
MONTEIRO, A. V. V. M.; VEGRO, C. L. R.; FERREIRA, C. R. R. P. T.; BARBOSA, M. Z.; NACHILUK, K.; RAMOS, R. C.; MIURA, M.; FAGUNDES, P. R. S.; SILVA, R. de O. P. e; FILHO, W. P. de C.; CARVALHO, Y. M. C. de. A Produção da Agropecuária Paulista: considerações frente à anomalia climática. Análises e Indicadores do Agronegócio, São Paulo, v. 10, n. 4, p. 1-16, abr. 2015.

MUNIZ, G. S.; GHIRALDELLO, L. Lazer e empresa: uma análise das publicações nacionais. Gestão e Conhecimento, PUC Minas, artigo 19, p. 1-21, 2014.

MUNIZ, K. G.; TELES, F. L. Armazenamento de produtos fitossanitários: estudo de caso na agroquímica. Revista Científica do Centro de Ensino Superior Almeida Rodrigues, Rio Verde, v. 1, n. 1, p. 22-34, 2013.

NASCIMENTO, L. F.; PESSOA, R. W. A. O lazer como ferramenta da qualidade de vida no trabalho. Revista Organização em Contexto, São Paulo, ano 4, n. 7, 2008.

NARCISO, M. G.; QUINTELA, E. D.; BARBOSA, F. R.; DEL PELOSO, M. J. Sistema de Alerta para a mosca-branca. In: I CONICBIO/II CONABIO/vI SIMCBIO, v. 2 Universidade Católica de Pernambuco - Recife, 2013. Resumos Expandidos [...]. Disponível em: http://www.unicap.br/simcbio/wp-content/uploads/2014/09/SISTEMA-DE-ALERTA-PARA-A-MOSCA-BRANCA.pdf. Acesso em: 07 fev. 2017.

NEXTON, L. H. Ethics and Sustainability: Sustainable Development and the Moral Life. Prentice Hall, Upper Saddle River, p. 117, 2003.

PALHARES, J. C. P. Novo desafio para avicultura: a inserção das questões ambientais nos modelos produtivos brasileiros. Avicultura Industrial, Itu, v. 96, ed. 1138, 2005.

PEREIRA, S. S.; CURI, R. C. Modelos de gestão integrada dos resíduos sólidos urbanos: a importância dos catadores de materiais recicláveis no processo de gestão ambiental. In: LIRA, W. S.; CÂNDIDO, G. A. (org.). Gestão sustentável dos recur- 
sos naturais: uma abordagem participativa [online]. Campina Grande: EDUEPB, 2013, p. 149-172.

RODRIGUES, G. S.; CAMPANHOLA, C. Sistema Integrado de Avaliação de Impacto Ambiental Aplicado a Atividades do Novo Rural. Pesquisa Agropecuária Brasileira, Brasília, v. 38, n. 4, p. 445-451, 2003.

RODRIGUES, G. S.; CAMPANHOLA, C.; KITAMURA, P. C.; IRIAS, L. J. M.; RODRIGUES, I. Sistema de Avaliação de Impacto Social de Atividades Agropecuárias (APOIA-SOCIAL). Cadernos de Ciência \& Tecnologia, Brasília: 2005.

ROSSETTI, J. P. Introdução à economia. 20. ed. São Paulo: Atlas, 922 p, 1990.

SAMULSKI, D. Esporte e desenvolvimento da personalidade. Revista Paulista de Educação Física, São Paulo, v. 6, p. 59-64, jul./dez. 1992.

SANGALLI, A. R.; SILVA, H. C. H.; SILVA, I. F.; SCHLINDWEIN, M. M. Associativismo na agricultura familiar: contribuições para o estudo do desenvolvimento no assentamento rural lagoa grande, em Dourados (MS), Brasil. Organizações Rurais e Agroindustriais, Lavras, v. 17, n. 2, p. 225-238, 2015.

SANTOS, E. O. Administração financeira da pequena e média empresa: manual do investidor do Instituto de Estudos Financeiros (IEF). São Paulo: Atlas, 1984.

SILVA, L. C. R. A importância da Administração Rural para o Desenvolvimento das Pequenas Propriedades Rurais. In: EITEC. Anais [...]. v. 2, n. 1. Picos: Instituto Federal de Educação, Ciência e Tecnologia do Piauí, 2013.

TOMEI, P. A.; SOUZA, D. A. A. L. Análise das barreiras que dificultam a transformação do agricultor familiar em empreendedor rural no contexto brasileiro. Revista Ibero-Americana de Estratégia, Araraquara, v. 13, n. 3. p. 107-122, 2014. 
TRENTIN, I. C. L.; PADILHA, P. R. P. Agroindústria familiar orgânica e estratégias de marketing e comercialização. In: CONGRESSO DA SOBER - Questões Agrárias, Educação no Campo e Desenvolvimento, 44., Anais [...]. Disponível em: http://ageconsearch.umn.edu/record/147142/files/426.pdf. Acesso em: 17 fev. 2018.

UDSEN, S. Folhosas, Seminário Nacional. Campinas, 2016. Disponível em: http:// www.abcsem.com.br/upload/arquivos/O_mercado_de_folhosas_Numeros_e_ Tendencias_-_Steven.pdf. Acesso em: 03 maio 2017.

VILAS BÔAS, R. L.; PASSOS, J. C.; FERNANDES, D. M.; BÜLL, L. T.; CEZAR, V. R. S.; GOTO, R. Efeito de doses e tipos de compostos orgânicos na produção de alface em dois solos sob ambiente protegido. Revista Horticultura Brasileira. Brasília, v. 22 , n. 1 , p. $28-34,2004$.

ZÁRATE, N. A. H.; VIEIRA, M. C. Produção da araruta 'Comum' proveniente de três tipos de propágulos. Ciência e Agrotecnologia, Lavras, v. 29, n. 5, p. 995-1000, 2005.

Recebido em: 18/09/2017 Aceito em: 06/06/2018 